\title{
A Determination of the Gamma-Ray Emission of Radium
}

\author{
Frank H. Attix and Victor H. Ritz
}

\begin{abstract}
Measurements of the $\gamma$-ray emission of radium (roentgens per milligram-hour at 1 centimeter) have been made by means of a graphite cavity ionization chamber. An auxiliary experimental examination of the stopping-power correction for the non-air-equivalence of the cavity wall is also described. The resulting average value for the $\gamma$-ray emission of radium (enclosed in an 0.5-millimeter platinum capsule) is $8.26 \pm 0.05$ roentgens per milligram-hour at 1 centimeter, which is based upon the conclusion that the stopping-power data of Bakker and Segre are consistent with the results of the auxiliary experiment.
\end{abstract}

\section{Introduction}

Field instruments for the measurement of the exposure dose or exposure dose rate of $\mathrm{X}$ - or $\gamma$-radiation usually require calibration against a primary standard. In the X-ray region between 50 and 500 $\mathrm{kv}$ it has already been pointed out in the 1956 report of the ICRU [1]* that primary standards of the free-air chamber type can be constructed with an absolute accuracy of about \pm 1 percent. However, the information required for the design of such instruments with this accuracy at the higher quantum energies, such as the $\gamma$-rays from $\mathrm{Co}^{60}$ or radium, is not yet available. Instead, the method of cavity ionization, utilizing the Bragg-Gray relation [2, 3], has generally been relied upon for measurements in this energy region.

Radium sources are frequently used for routine calibration purposes, by placing the instrument to be calibrated at a known distance from a capsule containing a known weight of radium. One must then know, from other measurements, what the exposure dose rate will be under these conditions. The ICRU report defines the specific $\gamma$-ray emission of a radioactive nuclide as "the exposure dose rate produced by the unfiltered $\gamma$-rays from a point source of that nuclide at a defined distance. The unit of specific $\gamma$-ray emission is the roentgen per millicuriehour (r/mch) at $1 \mathrm{~cm} . "$ For radium, the specific $\gamma$-ray emission is, instead, usually expressed in terms of the weight of radium element, i. e., roentgens per milligram-hour $(\mathrm{r} / \mathrm{mgh})$ at $1 \mathrm{~cm}$. It will be convenient to refer to this quantity as $K(\mathrm{Ra})$. For calibration purposes, radium sources are usually enclosed in capsules of platinum (10\% iridium), having walls $0.5 \mathrm{~mm}$ in thickness. Thus, a more useful figure for radium is the specific $\gamma$-ray emission modified by the attenuation in such a capsule wall. This has been given several names in the literature, such as dosage constant, $Q$-constant, $\gamma$-ray output, and Sievert dose, the latter being the most generally accepted. For present purposes we will use the symbol $k$ (Ra). For later reference it will be worthwhile to set down the following definition:

$\mathrm{k}(\mathrm{Ra})$ is the exposure dose rate in roentgens per hour at $1 \mathrm{~cm}$ from a point source of $1 \mathrm{mg}$ of radium element (in equilibrium with its daughter products),

\footnotetext{
*Figures in brackets indicate the literature references at the end of this paper.
}

enclosed in a platinum (10\% iridium) capsule of $0.5-\mathrm{mm}$ thickness, the surrounding air having no scattering or attenuating effect.

$k$ (Ra) cannot, at present, be calculated theoretically with an accuracy of better than a few percent, and it must, therefore, be measured experimentally. The most common currently accepted value is 8.4 $\mathrm{r} / \mathrm{mgh}$ at $1 \mathrm{~cm},{ }^{1}$ which is derived as a weighted average of a number of experimental determinations over a period of many years [4 to 42]. Cavity-type ionization chambers have been most frequently employed, but some free-air chamber measurements have also been attempted $[9,17,19,26,30,42]$. Even the most recent of these [42] is now known to have had substantial errors from electric field distortion and from ionization produced by scattered photons. Thus, the cavity ionization measurements appear to be the more reliable at present, and the $8.4 \mathrm{r} / \mathrm{mgh}$ figure is based principally upon these.

One of the main sources of uncertainty in cavity chamber measurements is related to the non-airequivalence of the chamber wall material. This gives rise to a correction factor, identified by the Bragg-Gray relation [2] as the ratio of the electron stopping power in the wall material to that in air. The evaluation of this factor, usually called $s$, is carried out by making use of the Bethe-Bloch stopping-power formula [43], which involves a term depending on the mean excitation potential $(I)$ for the atoms of the stopping material. It has not been adequately calculated theoretically, and must therefore be determined from experiments.

Laurence [34] computed $s$ for a number of wall materials, ${ }^{2}$ using the assumption that $I=13.5 Z$. His results have been widely employed in the interpretation of cavity chamber measurements, and in fact the value of $8.4 \mathrm{r} / \mathrm{mgh}$ for radium is consistent with the Laurence wall corrections. ${ }^{3}$

Bakker and Segre [44] and Mather and Segre [45] have measured $I$ in various materials through range measurements with fast protons. Their measurements indicate that $I / Z$ is not a constant for different atomic numbers $Z$. On the other hand, a recent

${ }^{1}$ At the National Physical Laboratory in the United Kingdom 8.3 is the value assumed for $k(\mathrm{Ra})$

${ }^{2}$ Note the error existing in Laurence's eq (8), the stopping-power formula, giving rise to an underestimation of $\&$ for graphite by about 1.1 percent and an overestimation for Al by about 0.6 percent. The second term in brackets in that equation should be $\ln \left[\left(k / 2^{3}\right)+k^{2}\right]$ instead of $\ln \left[k^{2}+(k / 2)\right]$.

3 See second footnote to table 5 . 
survey of existing measurements by Caldwell [46] and experiments of Bichsel and Mozley [47] show that $I / Z$ is approximately constant with $Z$, at least for $Z \geq 13$. An even more recent paper by Brandt [48] tends again to confirm the Bakker and Segre results. This difference will only be resolved by further experimental measurements of $I$, and at present brings about an uncertainty of the order of 1 percent in the interpretation of cavity ionization measurements.

The present experiment was initially undertaken with two purposes in mind:

(1) To provide a relatively precise determination of $k$ (Ra) by the cavity chamber method.

(2) To compare the abilities of the variously computed stopping-power corrections to reduce the experimental data for cavity chambers of differing wall materials (carbon and aluminum) to give a common value for the radium gamma-ray emission.

The experimental work was originally done in two parts. The first was the absolute measurement of the ionization produced in a graphite and an aluminum chamber at approximately 1-atm air pressure, at several measured distances from a known radium source. The second part was a study of the pressure dependence of the ionization in the same chambers, from 0.1 to $1 \mathrm{~atm}$, to determine the degree to which the cavity ionization was under the influence of the electrons originating in the chamber walls. The results of these two experiments were then combined to give the absolute ionization in each chamber as a function of air pressure.

Two unforeseen difficulties were encountered which rendered these results indeterminate. The first was that the ionization in the cavity chambers did not strictly obey the inverse square law as a function of distance between centers of source and chamber. This was found to be true after taking into account the air attenuation, scattering from the floor and other objects, and the size of the chamber and source. The most startling feature of this behavior was the fact that the $\mathrm{Al}$ chamber showed a greater divergence from inverse-square-law behavior than did the graphite. Thus, the ratio of ionizations in the two chambers (aluminum to carbon, of the same dimensions) was found to decrease with increasing distance from the source. The explanation of this effect will be discussed in the next section.

The other difficulty arose when the $\mathrm{Al} / \mathrm{C}$ ionization ratio was measured with several different radium sources, all having $0.5 \mathrm{~mm} \mathrm{Pt}$ capsule walls, but varying diameters. This ratio was found gradually to increase by 1 percent as the inside diameter of the source was decreased from 5.5 to $0.7 \mathrm{~mm}$. This effect may be the result of photoelectric interactions in the $\mathrm{Al}$ chamber wall by the bremsstrahlung produced within the source by $\beta$-rays, a point to be investigated further. It does, however, make the measurement of the $\mathrm{Al} / \mathrm{C}$ ionization ratio indefinite for radium. Moreover, it raises the question of whether the bremsstrahlung is to be included with the $\gamma$-radiation in the definition of $k(\mathrm{Ra})$. From practical considerations one concludes that it should be included, because it will always be present for radium sources enclosed in platinum capsules. Variations in the bremsstrahlung output with different source diameters will be taken into account approximately by the correction for attenuation in the radium salt, as measured by Whyte [51].

In view of the difficulties described above, it was decided to revise the approach to the measurement of $k(\mathrm{Ra})$ in three respects:

(A) The "distance effect" (nonobeying of inverse square law) was to be investigated with the object of eliminating the uncertainty resulting from it.

(B) Measurements with radium $\gamma$-rays were to be confined to the graphite chamber (eliminating the aluminum chamber for the reason outlined in the previous paragraph), using the information found in (A) to avoid the distance effect.

(C) Cobalt-60 $\gamma$-rays were to be used in place of radium $\gamma$-rays for the study of the stopping-power corrections for the non-air-equivalence of the chamber walls, to avoid the photoelectric effect. An additional chamber of copper, nearly identical in size to the graphite and aluminum chambers, was also constructed for inclusion in this study.

The results of this modified version of the experiment will be presented in the following sections. However, the original setup will first be described briefly to show how the distance effect entered the picture.

\section{Preliminary Measurements and the Distance Effect}

\subsection{Setup Initially Used for Radium Measurements}

Figure 1 is a photograph of the over-all arrangement. The cylindrical cavity chamber (graphite or aluminum), shown in figure 2 , was located at the end of a rigid, evacuated coaxial connector $2 \mathrm{~m}$ in length, which was connected to the input head of a vibrating reed electrometer. This head was enclosed in a 15-cm-thick lead housing which was supported by an electric lift truck, capable of raising the chamber to a height of $3 \mathrm{~m}$ above the floor. The radium source was supported at $2-m$ height by a paper stand, so constructed to contribute a minimum of $\gamma$-ray scattering. The chamber was located directly above the source so that the chamber axis was at right angles to a line joining their centers. The distance between centers (15 to $100 \mathrm{~cm}$ ) was determined by adding half the source and chamber diameters to the distance between their surfaces as measured by a cathetometer. An area of the concrete floor, 2.4 by $3.5 \mathrm{~m}$ in extent, was covered with a thickness of $6 \mathrm{~mm}$ of lead, to reduce the scattered radiation. Further details about the chambers, the radium source, and the corrections for scattering and attenuation will be given in section 3 .

\subsection{Initial Results}

Figure 3 is a graph of $i D^{2}$ as a function of $D$, where $i$ is the ionization in the cavity chamber, and $D$ is the center-to-center distance from source to chamber. Two corrections have been applied to these curves, accounting for attenuation by the air and scattering 


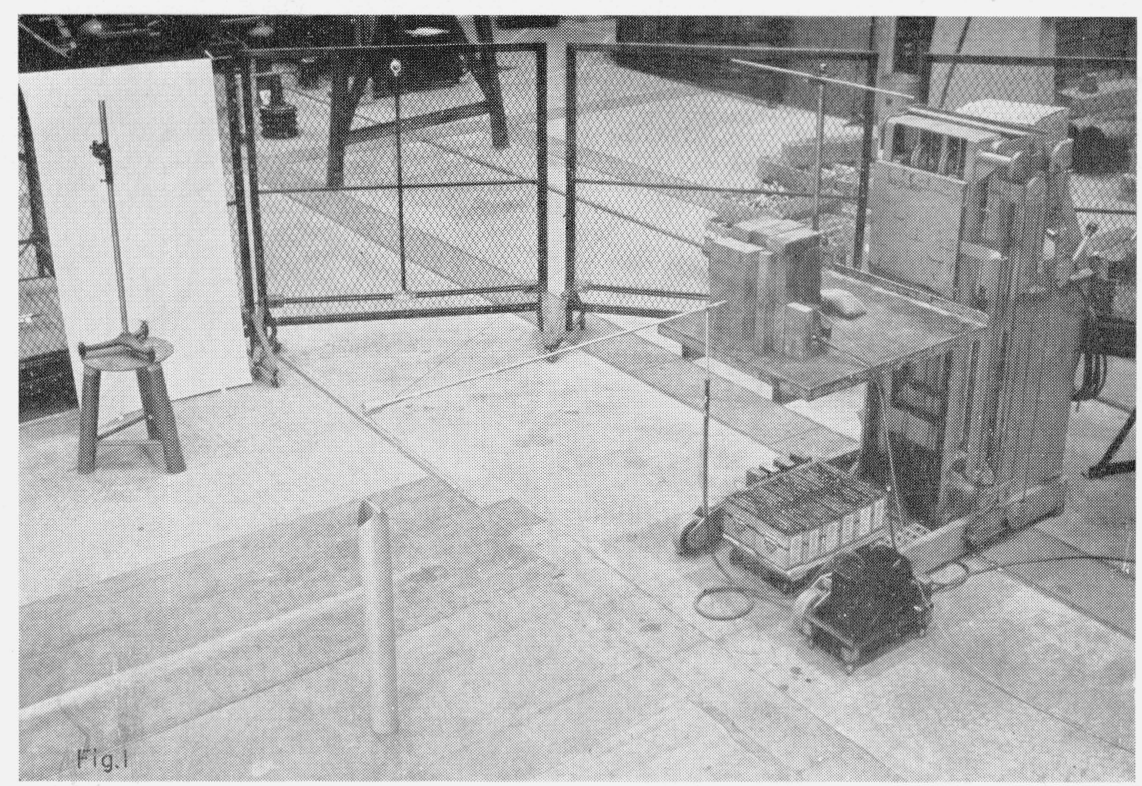

FIGURE 1. Setup used for the preliminary radium measurements.

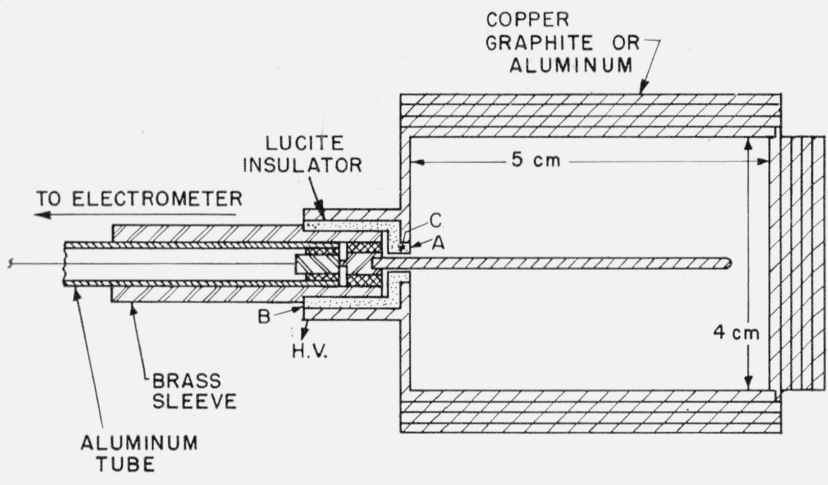

FIGURE 2. Diagram of cavity-ionization chambers.

The walls, of copper, aluminum, or graphite, were of variable thickness, and the central rod leading to the electrometer was, in each case, $3 \mathrm{~mm}$ in diameter and of the same material as the wall. The Lucite insulator was coated with graphite except for surfaces $\mathrm{A}$ and $\mathrm{B}$. The graphite coating at $\mathrm{C}$, the inside surface of the hole entering the chamber, was found to eliminate "soakage" effects when the voltage was first applied, and provided a guard ring for leakage of charge across surface A. Removing this graphite coating (from C) was found to have no effect on the steady state ionization in the chamber.

by the lead-covered floor. These were both very small and will be described in detail in section 3 . Even with these corrections, the curves show considerable variation as a function of distance, the variation being twice as great for the aluminum chamber as for the graphite.

A calculation was carried out to take into account the inverse square effect of the size of the chamber and source, using the general approach of Mayneord and Roberts [6] and Clark and Brar [50]. The

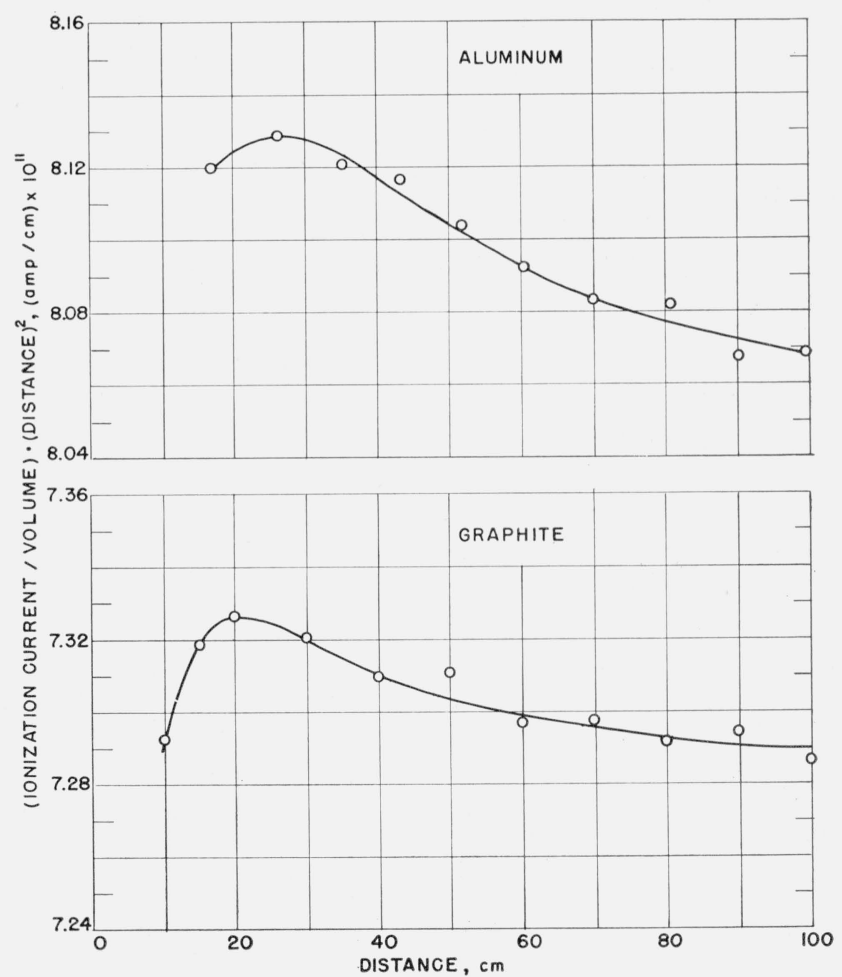

FIgURE 3. Distance dependence of ionization in the graphite and aluminum cavity chambers.

In each case, the radium source was located on a line perpendicular to the chamber axis and intersecting it at the geometrical center of the chamber. 


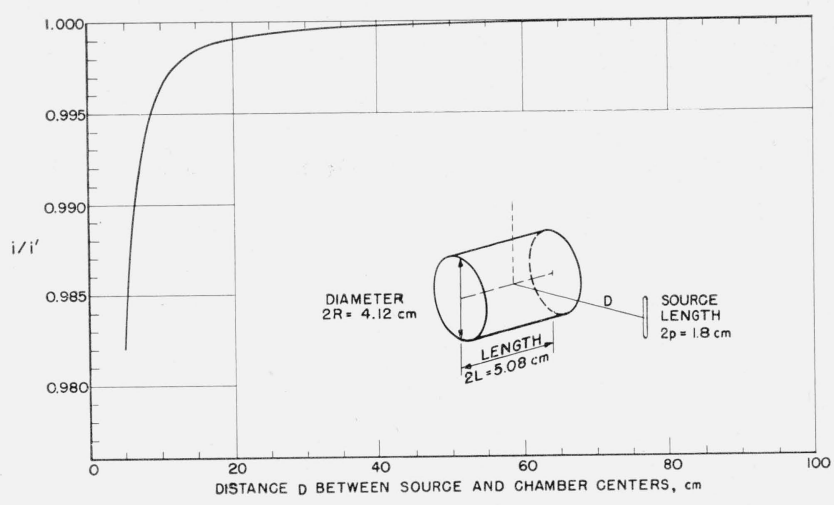

Figure 4. Calculated divergence from inverse square law to be expected with the indicated geometry.

geometry was that indicated in figure 4, and the integration was carried over the three dimensions of the chamber and the length of the source, by a series expansion ${ }^{4}$ in terms of $\left(i / D^{2}\right)$. The resulting expression for the ionization in the chamber was:

$$
\begin{aligned}
i=i^{\prime}[1+ & \frac{1}{D^{2}}\left(\frac{R^{2}}{2}-\frac{L^{2}}{3}-\frac{p^{2}}{3}\right) \\
& \left.\quad+\frac{1}{D^{4}}\left(\frac{L^{4}}{5}-\frac{2 R^{2} L^{2}}{3}+\frac{2 L^{2} p^{2}}{9}+\frac{R^{4}}{3}-\frac{R^{2} p^{2}}{3}+\frac{p^{4}}{5}\right)\right],
\end{aligned}
$$

where $i^{\prime}$ is the ionization to be expected for a point source and point chamber separated by distance $D$, $2 L$ is the internal length of the chamber, $R$ its internal radius, and $2 p$ the active length of the source. In the present case, where $2 L$ is $5.08 \mathrm{~cm}$, $R$ is $2.06 \mathrm{~cm}$, and $2 p$ is $1.8 \mathrm{~cm}$, the ratio $\left(i / i^{\prime}\right)$ is as indicated in figure 4. The drop at small values of $D$ is at least qualitatively shown by the curves in figure 3. However, $\left(i / i^{\prime}\right)$ is flat within 0.1 percent for $D>20 \mathrm{~cm}$, unlike the results observed with these chambers. Such a calculation as this, of course, has nothing to say about the difference in slope of the aluminum and graphite curves, and ignores the fact that most of the cavity ionization is produced by electrons originating within the chamber walls. A more elaborate calculation taking these factors into account has not been attempted, and is probably not feasible with information now available.

The attenuation of $\gamma$-rays in the chamber walls was measured at different distances by the conventional method of varying the wall thickness, but the result was found to be independent of $D$. Extracameral collection of ionization and ion-recombination losses were also found experimentally to make a negligible contribution to the distance dependence of the ionization.

It appears then that the observed distance effect is not explained by the usual influencing factors. It was decided to explore the problem further by increasing the source-to-chamber distance to values

4 The method of integrating was suggested by L. V. Spencer.

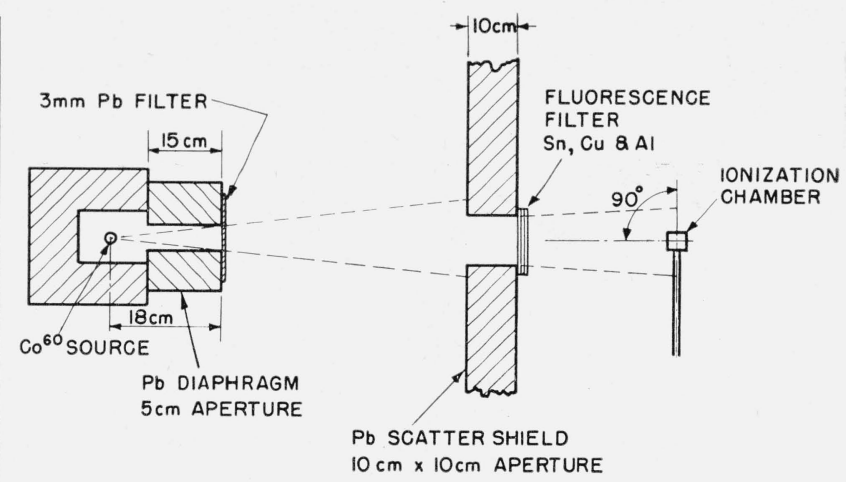

FIGURE 5. Arrangement used for measuring the relative vonization produced by cobalt-60 $\gamma$-rays in copper, aluminum, and graphite chambers.

The scatter shield removed scattered radiation produced in the air when the source was at large distances.

greater than $1 \mathrm{~m}$. In order to do this, it was necessary to employ larger $\mathrm{Co}^{60}$ sources ( 1 and 10 curies) to provide sufficient ionization for accurate measurement, and to collimate the beam to avoid complicating the issue with $\gamma$-ray scattering from surrounding objects. The geometry was as shown in figure 5 .

Because the exact position of the source within the lead housing was not known, and because of scattering from the filter, only the ratios of ionizations in chambers of differing wall materials were considered as being significant. These ratios, relative to the graphite chamber, are shown in figure 6 (for $90^{\circ}$ geometry), including the data for a copper chamber similar in dimensions to the graphite and the aluminum chambers, but with walls $1 \mathrm{~mm}$ in thickness. These data were taken with a filter of $3 \mathrm{~mm} \mathrm{~Pb}+2.4$ $\mathrm{mm} \mathrm{Sn}+0.5 \mathrm{~mm} \mathrm{Cu}+0.8 \mathrm{~mm} \mathrm{Al}$ to eliminate any scattered and fluorescent radiation originating in the source, housing, and diaphragm. Additional lead in the filter was found to have no effect upon the ratios; similarly, the presence of the fluorescence filter did not influence the results. Without any filter, the curves were of the same shape but somewhat higher due to the presence of low-energy radiation. The $\mathrm{Al} / \mathrm{C}$ curve for $90^{\circ}$ geometry in figure 6 decreases by 1.5 percent over the indicated range of distances, whereas the corresponding decrease of the $\mathrm{Cu} / \mathrm{C}$ ratio is 5 percent. Neither curve shows any tendency to flatten out rapidly with distance, indicating that their slopes cannot be explained on the basis of a fixed difference in the effective centers of ionization in chambers of different wall materials. However, this behavior at large distances does suggest the possibility that the end walls of the chambers might in some way be responsible, perhaps through attenuation, because of the grazing incidence of the $\gamma$-rays upon those walls.

As a test of this hypothesis, the setup in figure 5 was changed to give a $50^{\circ}$ instead of $90^{\circ}$ angle between the chamber axis and the direction from which the rays were incident. With this geometry the $\mathrm{Al} / \mathrm{C}$ and $\mathrm{Cu} / \mathrm{C}$ curves were both flat within \pm 0.2 percent, as shown in figure 6 . The work was repeated at $70^{\circ}$, to find out if there was any depend- 


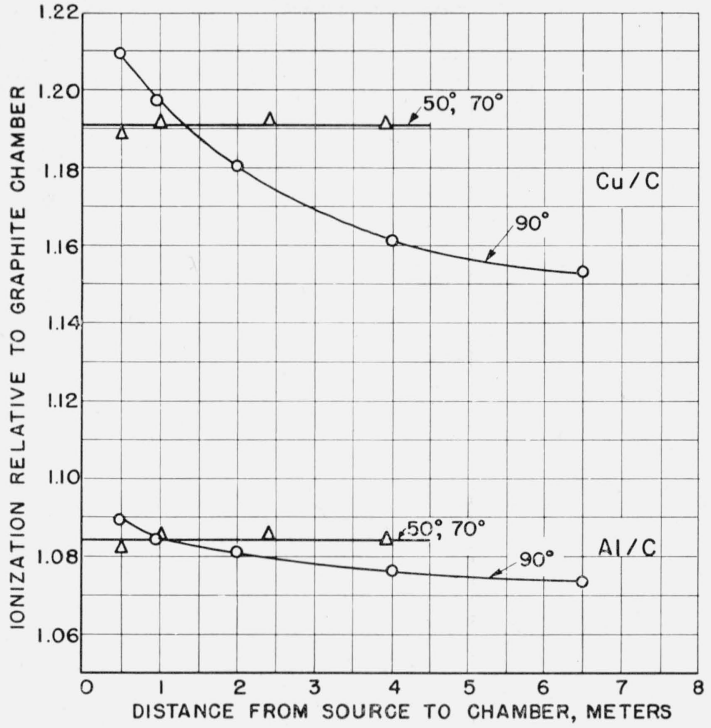

FIGURE 6. Ionization in the copper and aluminum chamber relative to that in graphite for cobalt-60 $\gamma$-rays.

The indicated angles are those between the chamber axis and the line joining the centers of the source and chamber.

ence on (nonglancing) angle, giving identical results. Thus, it appears clear that the distance effect is related to geometrical situations where the $\gamma$-rays strike the chamber at grazing incidence with respect to an appreciable area of chamber wall. ${ }^{5}$ It is not definitely established, however, that attenuation is wholly responsible. It can account for the behavior at large distances, where the attenuation of $\gamma$-rays in the end walls of the copper chamber, for example, would certainly be much larger than in the graphite chamber because of the greater density of copper. ${ }^{6}$ Thus, the copper end walls would contribute less than their share of ion-producing electrons, and the ionization would be reduced. However, as the distance from the source is diminished, one would expect this effect to become smaller, so that $\mathrm{Cu} / \mathrm{C}$ and $\mathrm{Al} / \mathrm{C}$ ratios would approach the values obtained at $50^{\circ}$ and $70^{\circ}$. This is clearly not the case, as figure 6 indicates higher $\mathrm{Cu} / \mathrm{C}$ and $\mathrm{Al} / \mathrm{C}$ ratios at $90^{\circ}$ than at $50^{\circ}$ or $70^{\circ}$ for distances less than about $1 \mathrm{~m}$. At present there is no satisfactory explanation to account for this, and it therefore deserves further study.

For present purposes, however, the distance effect can be avoided by orienting the chamber so as to eliminate glancing-angle incidence of the $\gamma$-rays, thus obtaining unambiguous results for $k(\mathrm{Ra})$, and for the experimental check of the stopping-power correction.

$5 \mathrm{G}$. N. Whyte [51] has also observed this effect, using cylindrical chambers with the $\gamma$-rays arriving at $0^{\circ}$ with respect to the chamber axis. Greening's measurements [52] also show the effect to a small extent.

${ }^{6}$ Note that the decrease in the $\mathrm{Cu} / \mathrm{C}$ ratio (for $90^{\circ}$ geometry) over the range of distances shown in figure 6 is larger than the change in $\mathrm{Al} / \mathrm{C}$ by the factor 3.1 , which is nearly the ratio of densities of $\mathrm{Cu} / \mathrm{Al}(3.3)$. Moreover, the distance. variation of $i D^{2}$ shown in figure 3 is about 1.8 times as great for Al as for graphite; the corresponding density ratio is 1.6 .

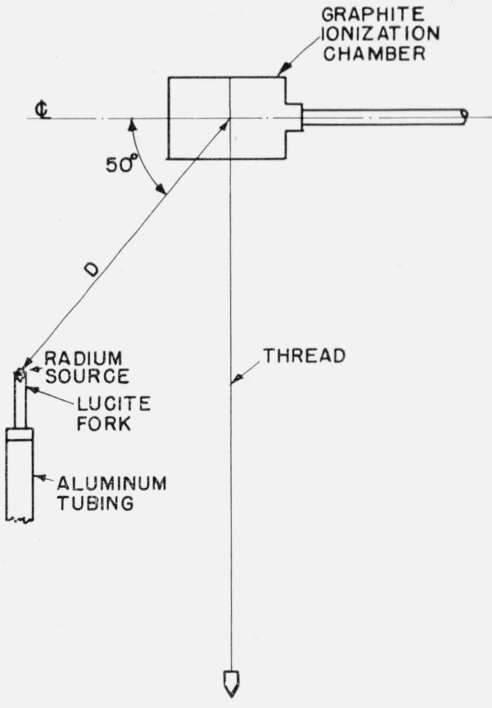

FIGURE 7. Geometry employed in the final radium measurements.

\section{Final Radium Measurements}

\subsection{General Setup}

The arrangement of the experiment was the same as that shown in figure 1 and described in section 2, except that the source was not directly below the chamber, and a $2-\mathrm{m}$ stand of aluminum and Lucite was used in place of the paper tube. Figure 7 gives a schematic elevation of the final arrangement, in which there was a $50^{\circ}$ angle between the chamber axis and the line joining centers of the source and chamber. The distance was determined by using two cathetometers, one vertical and the other horizontal. A fine thread supporting a plumb bob was suspended from the center of the chamber, positioned by a narrow groove cut into the chamber wall. This provided a reference point for the horizontal cathetometer measurement. Because of the time involved in making cathetometer readings before and after every ionization measurement, it was decided to substitute an exact replica of the radium source for this purpose to avoid unnecessary $\gamma$-ray exposure to the experimenters. This necessitated a more stable support for the source than the paper stand used previously.

The experimental setup was located in an airconditioned room where the temperature fluctuations did not exceed a few tenths of a degree centigrade during the working day. Frequent readings were taken of the ambient temperature, ${ }^{7}$ pressure and relative humidity, and all ionization data normalized to dry air at $0^{\circ} \mathrm{C}$ and a pressure of $760 \mathrm{~mm}$ of $\mathrm{Hg}$. The room was $37 \mathrm{~m}$ long, $18 \mathrm{~m}$ wide, and $18 \mathrm{~m}$ high, the closest wall being $6 \mathrm{~m}$ distant.

7 Blackening the bulb of the thermometer had no effect on its reading, indicating that radiant heat in the neighborhood of the graphite chamber was negligible. 


\subsection{Ionization Chamber}

The graphite-walled ionization chamber was constructed as indicated in figure 2. Its dimensions were measured by a precision micrometer and its volume calculated to be $67.50 \mathrm{~cm}^{3}$, allowing for the volume of the graphite collecting electrode, which was approximately $3 \mathrm{~mm}$ in diameter and extended into the chamber $3.7 \mathrm{~cm}^{8}$

The purity of the graphite was checked spectroscopically and found to exceed 99.9 percent. A calculation of the effect of the remaining impurities (mainly iron) showed them to be entirely negligible. The density of the graphite was $1.7 \mathrm{~g} / \mathrm{cm}^{3}$, and it was found to be easily machinable to close tolerances.

\subsection{Measurement of Ionization Current}

A vibrating reed electrometer was used as a null detector in the current measurements, in the Townsend charge-compensation method [53]. The average rate of charge was measured during timed runs of about 60 sec duration by collecting the charge on a known capacitor $(1014.8 \mu \mu \mathrm{f} \pm 0.05$ percent). The compensating potential was applied to the capacitor by a calibrated potentiometer accurate to \pm 0.05 percent.

Time measurements were made by electronically counting the cycles in a $1 \mathrm{kc}$ signal accurate to 1 part in 100,000. Runs were started and stopped by a relay in series with the electrometer milliammeter, using a device described by Costrell and Attix [54].

A potential of $\pm 1,000 \mathrm{v}$ was applied to the chamber wall to collect the ionization. This was sufficient to reduce the recombination losses to 0.1 percent, as determined from extrapolation on a plot of 1 /ionization versus 1 /collecting voltage. This 0.1 percent loss was corrected for in the calculation of $k(\mathrm{Ra})$, and was independent of source-chamber distance. All ionization measurements were done with both polarities applied to the chamber, and the observed currents averaged to eliminate the effects of extracameral ionization generated in the connections. Usually the two polarities gave currents agreeing within a few tenths of a percent.

\subsection{Radium Source}

The principal radium source used in the absolute gamma-ray output measurement was NBS Secondary Standard No. 33420, containing nominally $100 \mathrm{mg}$ of radium element. The platinum (10\% iridium) capsule was cylindrical in shape, having $22 \mathrm{~mm}$ overall length, 18-mm active length, 3 -mm outer diameter, and $0.5-\mathrm{mm}$ wall thickness, with tolerances of \pm 1 percent on these dimensions. It was completely filled with a homogeneous mixture of $142 \mathrm{mg}$ of radium sulfate and $15 \mathrm{mg}$ of barium sulfate, packed to a density of about $2.78 \mathrm{~g} / \mathrm{cm}^{3}$.

This source had been previously compared with the primary radium standards on the NBS Standard electroscope. ${ }^{9}$ It had been found to have $\gamma$-radiation equivalent to that of $94.40 \mathrm{mg}$ ( \pm 0.3 percent) of

\footnotetext{
${ }^{8} \mathrm{~A}$ check on the volume of the aluminum chamber by water weighing was found to give agreement with the micrometer measurement to 4 parts in 10,000 This was not done with the graphite because of its porosity.

$\theta$ This is essentially an aluminum-walled ionization chamber with thick $(1 \mathrm{~cm})$ lead outer walls to filter out the soft $\gamma$-rays.
}

radium element, in equilibrium with its products and contained in Thuringian glass $0.27 \mathrm{~mm}$ in thickness. ${ }^{10}$ The $\gamma$-rays from the primary standard source are attenuated by 0.5 percent [56] in the glass wall and the radium salt itself. Hence, the $\gamma$-radiation from the secondary standard is equivalent to that from a bare, point source of $(94.40 \mathrm{mg}) \times(0.995)=93.93 \mathrm{mg}$ (where only the harder $\gamma$-ray components are compared).

The actual radium content can be obtained by considering the physical dimensions of the source. Its nonpoint nature has two consequences: (1) Attenuation in the radium and barium salts; and (2) an increase in the effective thickness of the platinum wall because of its curvature. (From calculations by Owen and Naylor [57] our 0.5-mm platinum wall has an effective thickness of $0.56 \mathrm{~mm}$.) The corrections are made in two steps, namely for:

(a) Attenuation in $0.56 \mathrm{~mm}$ platinum, using the coefficient $0.93 \mathrm{~cm}^{-1}$ for heavily filtered $\gamma$-rays. ${ }^{11}$ This correction factor is $1 / 0.949$.

(b) Attenuation in the salt for heavily filtered $\gamma$-rays. Interpolating Whyte's data for the components of the salts (Ra,Ba,S,O) one obtains an effective attenuation coefficient $\mu$ of $0.124 \mathrm{~cm}^{-1}$. From calculations of Paterson, Walsh, and Higgins [59], the correction factor becomes $1 / 0.989_{5}$.

Applying corrections (a) and (b) to the $93.9_{3}-\mathrm{mg}$ figure, the resulting radium content is $100.0_{0} \pm 0.5$ mg. As a check on this figure, a calorimetric comparison with primary radium standard No. XIV was made by W. B. Mann, using the Peltier-effect twin microcalorimeter that was built for the comparison of a number of Hönigschmid standards [60]. This yielded a radium content of $99.6_{2} \pm 0.3 \mathrm{mg}$, which, being more directly obtained, is probably the more accurate of the two values. Thus, the two values have been averaged by weighting the calorimetric result twice, giving $99.7_{5} \pm 0.3 \mathrm{mg}$ as the radium content as of October $1,1956$.

If this radium were located at a point centered within $0.5-\mathrm{mm}$ platinum walls, no further correction would be necessary; the actual radium content would be used in calculating $k(\mathrm{Ra})$. Instead, further corrections must be applied to obtain the effective radium content, taking into account the attenuation in the excess platinum wall thickness (due to its curvature), and the attenuation in the salt. For this purpose, the attenuation coefficients of Whyte [58] for lightly filtered radium $\gamma$-radiation were used, as follows:

a. Attenuation by the salt mixture itself, for radium $\gamma$-rays filtered by $0.56 \mathrm{~mm}$ platinum $\left(\mu=0.170 \mathrm{~cm}^{-1}\right)$, was calculated to give a correction factor of 0.986 .

10 As of October 1, 1956. The radium contents of the primary standard sources were taken to be those given by the weighings of Hönigschmid, as described by Davenport et al. [55].

${ }^{11} \mathrm{G}$. N. Whyte has generously supplied, in private correspondence, the attenuation coefficients used for source corrections. His recent measurements were made with detectors of two types: (1) An ionization chamber with thick lead walls and an aluminum inside liner, and (2) a Victoreen chamber with thick Bakelite walls [58]. The measurements with (1) give the attenuation coefficients for heavily filtered radium $\gamma$-rays, whereas (2) gives those coefficients applying to lightly filtered $\gamma$-rays. Whyte's source was $30 \mathrm{mg}$ of radium element in a glass capsule $2 \mathrm{~mm}$ in outside diameter and $0.25 \mathrm{~mm}$ in wall thickness. We will assume here that the radium salt plus glass wall had negligible filtering action on the radium spectrum compared to that of $0.5 \mathrm{~mm}$ of platinum. 
b. Attenuation in the excess platinum wall thickness due to curvature (i. e., $0.56-0.50=0.06 \mathrm{~mm}$ $\mathrm{Pt}$ ), for $\gamma$-rays filtered by the salt, plus $0.5 \mathrm{~mm}$ platinum, gave a correction factor of 0.991 .

Applying these corrections to the true radium content of $99.7_{5} \mathrm{mg}$ gives an effective content of $97.4_{6} \mathrm{mg}$ of radium element. This is the figure used in calculating $k(\mathrm{Ra})$.

A check of the $\gamma$-ray output as the source was rotated about its axis indicated that it was isotropic within \pm 0.1 percent.

As an over-all check on the source corrections, a second source of different dimensions was also used for the $k(\mathrm{Ra})$ measurement. This was NBS Secondary Standard No. 33418, containing nominally $25 \mathrm{mg}$ of radium in a platinum $(10 \%$ iridium) capsule, $13 \mathrm{~mm}$ in over-all length, $9 \mathrm{~mm}$ in active length, $2.5 \mathrm{~mm}$ in external diameter, and having a wall thickness of $0.5 \mathrm{~mm}$. By the same procedure described above for the other source (except for the omission of the calorimetric measurement of the radium content) the effective content of this source was found to be $24.3_{6} \mathrm{mg}$ of radium element, as of October 1, 1956.

\section{Corrections for Scattering and Attenua- tion of the $\gamma$-Rays}

\subsection{Chamber Walls and Connector}

The thickness of the chamber walls was more than enough to insure electronic equilibrium. ${ }^{12}$ The cylindrical-wall thickness was $6.1 \mathrm{~mm}$, the blank end wall $4.8 \mathrm{~mm}$, and the connector end wall $3.2 \mathrm{~mm}$. Attenuation and scattering in each of the walls was examined by increasing the thickness, using a series of graphite sleeves and disks, and extrapolating the observed ionization to zero wall thickness. These pieces were added as shown in figure 2 , except that, for the $50^{\circ}$-angle geometry, they were placed in echelon fashion in line with the incoming $\gamma$-rays to avoid leaving a gap at the corner of the chamber. Scattered $\gamma$-radiation from the connector end wall and the connector was measured with the $50^{\circ}$ angle altered to $130^{\circ}$, giving a "mirror image" of the usual geometry. Graphite disks and a replica of the chamber connecting assembly were then placed against the blank end of the chamber and their effect on the ionization observed. By this method, the scattered $\gamma$-radiation from the actual connector and connector end wall was estimated to be 0.2 percent. Attenuation in the other walls of the chamber amounted to some 3.1 percent, ${ }^{13}$ giving an over-all correction of 2.9 percent for attenuation and scattering of $\gamma$-rays in the walls and connector.

Mayneord [62] has pointed out that the effective thickness of the wall, with respect to the $\gamma$-ray attenuation, is somewhat less than the actual thickness because the ionizing electrons are produced within the wall material. From data given by Gray [8],

12 The need for electronic equilibrium is discussed elsewhere, for example by Wilson 61]. Electronic equilibrium is a prerequisite for the measurement of exposure dose.

(3) Including a very small $(<0.1 \%)$ calculated correction for attenuation in the central rod in the chamber. this reduction in effective thickness is about $0.26 \mathrm{~mm}$ of graphite for radium $\gamma$-rays. This results in a 0.1 percent decrease in the above attenuation correction of 2.9 percent, changing it to 2.8 percent. ${ }^{14}$

\subsection{Air Scattering and Attenuation}

The "true" absorption coefficient $\sigma_{\mathrm{a}}$ for radium $\gamma$-rays is 0.32 percent per meter of air at 1 atm and $20^{\circ}$ C. However, the effective coefficient for attenuation near an isotropic point source will be less because of the contribution of backscattered rays. This coefficient was estimated to be about 0.2 percent per meter, obtained from a calculation assuming only single scattering. A somewhat lower value would result if multiple scattering were taken into account, but the correction is not important for the small distances $(<1 \mathrm{~m})$ used in this experiment.

\subsection{Scattering From the Floor}

Radiation scattered from the floor was measured by suspending the radium source in a small paper cradle attached by threads to the chamber. The height $d$ of the source above the floor was then varied, keeping constant the distance $D$ from source to chamber, and observing the ionization in the chamber. It was found that a 6 -mm layer of lead on the thick concrete floor reduced the scattering by a factor of $1 / 3$. Additional lead thickness made no difference.

Such a curve of ionization versus $d$ is shown in figure 8 , for $D=100 \mathrm{~cm}$ and the lead covering on the floor. ${ }^{15}$ The floor-scattered radiation arriving at the chamber with $D=100 \mathrm{~cm}$ and $d=200 \mathrm{~cm}$ is evidently about 0.2 percent. This applies strictly only when the source is directly below the chamber, as in the preliminary radium measurements (fig. 1). However, it is easy to show that changing to $50^{\circ}$ geometry, as in figure 7 , does not appreciably change the floor-scatter correction for a given $d$ and $D$, if the scattering is small.

\footnotetext{
14 Corrections such as these (but measured with $\mathrm{Co}^{60} \gamma$-rays) were also included in the data presented in figure 6 . They were nearly the same as for radium. ${ }_{15}$ Actually the curve represents data obtained with several different $D$ values. It was found that these could be normalized to fall on the same curve if the points were plotted with $d(10 \mathrm{~cm} / D) \mathrm{cm}$ as the abscissa. In other words, the amount of scatter "scales" with the ratio of distances $d / D$, as one might expect.
}

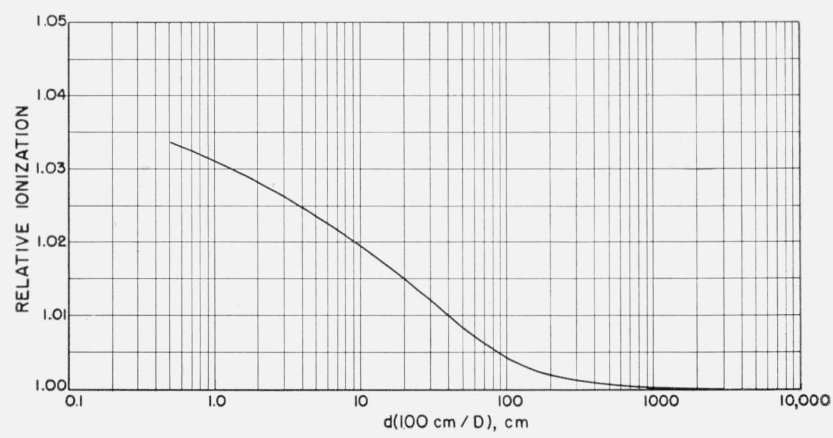

FIGURE 8. Scattered $\gamma$-radiation from a lead-covered floor.

The radium source is located at a distance $d$ above the floor, and the graphite. cavity chamber at a distance $D$ above the source. (See footnote 15 .) 


\subsection{Scattered Radiation From Other Objects}

In addition to the sources of scattered radiation which have already been treated, the following were also considered.

The scattered radiation from the Lucite holder for the radium source was measured by doubling the thickness of the two blades of the "fork", and was found to be less than 0.1 percent.

The scattered radiation from all other objects together (including the lift truck and a concrete wall behind which the electrometer operator sat), was measured by interposing a lead block $10 \mathrm{~cm}$ square and $15 \mathrm{~cm}$ in thickness halfway between the source and chamber. This was supported on a light aluminum stand, which itself was observed to introduce no additional scattering.

With a distance of $94 \mathrm{~cm}$ between the source and chamber, the ionization with the lead block in place was found to be 0.7 percent of that obtained with the lead block removed. The scattering from the air (assumed to extend a great distance in all directions) amounts to some 0.6 percent of the unobstructed reading, while the lead-covered floor contributes another 0.2 percent. These total 0.8 percent, exceeding the observed ionization by 0.1 percent, which may be considered as agreement within experimental error. Thus the scattering by other objects is negligibly small.

\section{Experimental Results}

Table 1 presents the ionization in $\mathrm{esu} / \mathrm{cm}^{3}-\mathrm{mgh}$ (at $1 \mathrm{~cm})^{16}$ measured in the graphite chamber with geometry as in figure 7 .

TABLE 1. Ionization results with the graphite chamber

\begin{tabular}{|c|c|c|}
\hline Source & $D$ & $\begin{array}{c}\text { esu/ } \mathrm{cm}^{3}-\mathrm{mgh} \\
\text { at } 1 \mathrm{~cm}\end{array}$ \\
\hline & & \\
\hline$m g$ & $\mathrm{~cm}$ & \\
100 & 31 & 8.25 \\
100 & 50 & 8.26 \\
100 & 72 & 8.28 \\
100 & 94 & 8.24 \\
25 & 32 & 8.26 \\
\hline Average & & 8.257 \\
\hline
\end{tabular}

All the corrections for attenuation and scatter discussed above have been taken into account. There is apparently no systematic variation of the data as a function of $D$, this effect having been eliminated by the geometry. The check at $32 \mathrm{~cm}$ with the $25 \mathrm{mg}$ source is in good agreement with the data obtained with the $100-\mathrm{mg}$ source. The average of $8.25_{7}$ $\mathrm{esu} / \mathrm{cm}^{3}-\mathrm{mgh}$ at $1 \mathrm{~cm}$ need only be multiplied by a stopping-power correction for the non-air-equivalence of graphite to give $k(\mathrm{Ra})$.

Because of the existing uncertainty in the stoppingpower correction, an auxiliary investigation was undertaken in an attempt to shed some light on that problem.

16 Note that 1 coulomb $=2.998 \times 10^{9} \mathrm{esu}$

\section{Auxiliary Investigation of the Stopping- Power Correction}

From the Bragg-Gray relation [2], the ionization $J_{\text {air }}$ produced by $\gamma$-rays in free air is related to the ionization $J_{Z}$ produced in a small cavity chamber with walls of atomic number $Z$ by the equation

$$
J_{\text {air }}=J_{Z} s_{\text {air }}^{Z},
$$

where $s_{\text {air }}^{Z}$ is the ratio of the effective electronic stopping power (per electron $/ \mathrm{cm}^{2}$ ) in the wall and air respectively, and it is assumed that only the Compton effect is active in delivering energy. This assumption holds for graphite, aluminum, and copper with cobalt-60 $\gamma$-rays. (Davisson and Evans [64] found no photoelectric effect in copper for cobalt-60 $\gamma$-rays.) If one measures $J_{Z}$ for cavities having different wall materials, under identical conditions of irradiation, the respective values calculated for $J_{\text {air }}$ should coincide if the stopping-power data (and the cavity theory) employed in calculating $s_{\text {air }}^{Z}$ are correct.

Such measurements were made with cobalt-60 $\gamma$-rays in the course of the distance-effect study, and are shown in the form of $J_{\mathrm{Cu}} / J_{\mathrm{C}}$ and $J_{\mathrm{A}} / J_{\mathrm{C}}$ in figure 6 . In order to apply properly the theoretical stoppingpower factors $s_{\text {air }}^{Z}$ to these data, further measurements at reduced air pressures were necessary, to ascertain whether the cavities were small enough to satisfy the requirements of cavity theory. Both the conventional Bragg-Gray theory and the Spencer cavity theory [49] require the cavity to be small in comparison with the average range of the primary electrons. Thus the following experiment was performed.

\section{General Setup}

The geometry was that shown in figure 5, except that the chamber in each case was enclosed within a cylindrical aluminum tank $7.3 \mathrm{~cm}$ in inner diameter, $25 \mathrm{~cm}$ in length, and having a side-wall thickness of $1.6 \mathrm{~mm}$. The beam was oriented at $50^{\circ}$ from the chamber axis.

The air in the tank was dried by passing it slowly through drying columns containing magnesium perchlorate. Pressures were measured by means of a mercury U-tube $12 \mathrm{~mm}$ in internal diameter, the other leg of which was continuously pumped to maintain it at about $0.1 \mathrm{~mm}$ of $\mathrm{Hg}$. This low pressure was measured by a McLeod gage, taking care to eliminate vapors by means of a cold trap $\left(\mathrm{CO}_{2}\right.$ and trichlorethylene). Another cold trap separated the U-tube from the tank itself. The heights of the menisci were measured to $\pm 0.1 \mathrm{~mm}$ of $\mathrm{Hg}$ with a cathetometer. A reservoir tank of 65 liters was connected to the system to provide "ballast", making it possible to maintain pressures constant to $0.1 \mathrm{~mm}$ of $\mathrm{Hg}$ for hours. Due care was exercised to avoid transient temperature effects after changing the tank pressure.

Most of the measurements were made with the cobalt-60 source (with filter) at $50 \mathrm{~cm}$ from the chamber. However, a check was made of the pressure dependence of the graphite chamber with a smaller 
cobalt-60 source at a distance of $8 \mathrm{~cm}$, yielding the same result within 0.1 percent. One may conclude that a geometrical effect such as that observed by White et al. [10] with spherical-shell chambers, is of no consequence here.

The effect of scattered radiation produced by the thin aluminum tank may be assumed to be of second order with respect to the pressure dependence of the cavity ionization.

\section{Experimental Results}

Ionization was measured in each chamber at pressures ranging from 0.1 to $1 \mathrm{~atm}$. At each pressure and with each chamber, a saturation curve was taken with voltages up to $1,000 \mathrm{v}$. These are shown plotted as $p / i$ versus $1 / v$ in figures $9 \mathrm{a}, 9 \mathrm{~b}$, and $9 \mathrm{c}$. By plotting against the reciprocal of the applied voltage, it is possible to extrapolate to $1 / v=0$ to obtain the current at complete saturation, if the data are carried to sufficiently large voltages to give linear behavior [65]. Thus, the effect of variation of the degree of saturation with pressure can be eliminated.

Ordinarily the current measurements were made with both polarities and averaged. However, some gas multiplication was observed at high negative voltage and low pressure, causing the negative current to increase and diverge from the positive current. At 0.2 atm with $-1,000 \mathrm{v}$ applied to the chamber wall, and at 0.1 atm with $-300 \mathrm{v}$, the increase was a few tenths of a percent. At 0.1 atmos, $-1,000 \mathrm{v}$, it was about 9 percent. Onset of gas multiplication in air occurs at $20 \mathrm{v} \mathrm{cm}^{-1}(\mathrm{~mm} \mathrm{Hg})^{-1}$ [66], or for the present chambers (assuming them to be simple cylinders) at $-600 \mathrm{v}$ for $0.1 \mathrm{~atm}$, in reasonable agreement with observations. Because the multiplication occurs only in a small volume around the central electrode, it will be negligible for positive voltage on the chamber wall until it becomes very large for negative voltage. Thus, it was possible to avoid the effect by relying upon the positive current readings in cases where the negative current was influenced by multiplication.

The currents per unit pressure at $1 / v=0$ are plotted (as solid curves) in figure 10 as a function of the air pressure $\left(\right.$ at $0^{\circ} \mathrm{C}$ ) for copper, aluminum, and graphite. These curves are normalized to each other at room pressure $(\approx 0.92 \mathrm{~atm})$ by means of the ratios $\mathrm{Cu} / \mathrm{C}=1.191$ and $\mathrm{Al} / \mathrm{C} \doteq 1.084$ obtained from figure 6 . The graphite curve shows a slight decrease with decreasing pressure, whereas aluminum and copper both have a pronounced rise. It would be difficult to extrapolate these curves to zero pressure with any confidence in the result, because of the increasing slope at low pressures.

\section{Comparison with Cavity Theory}

In calculating the values of $s_{\text {air }}^{\mathrm{Z}}$, the electron stopping-power formula of Bethe [43] was employed. Two sets of values for $I$, the mean excitation potential of the stopping material, were used with the Bethe formula; those of Bakker and Segre [44] and
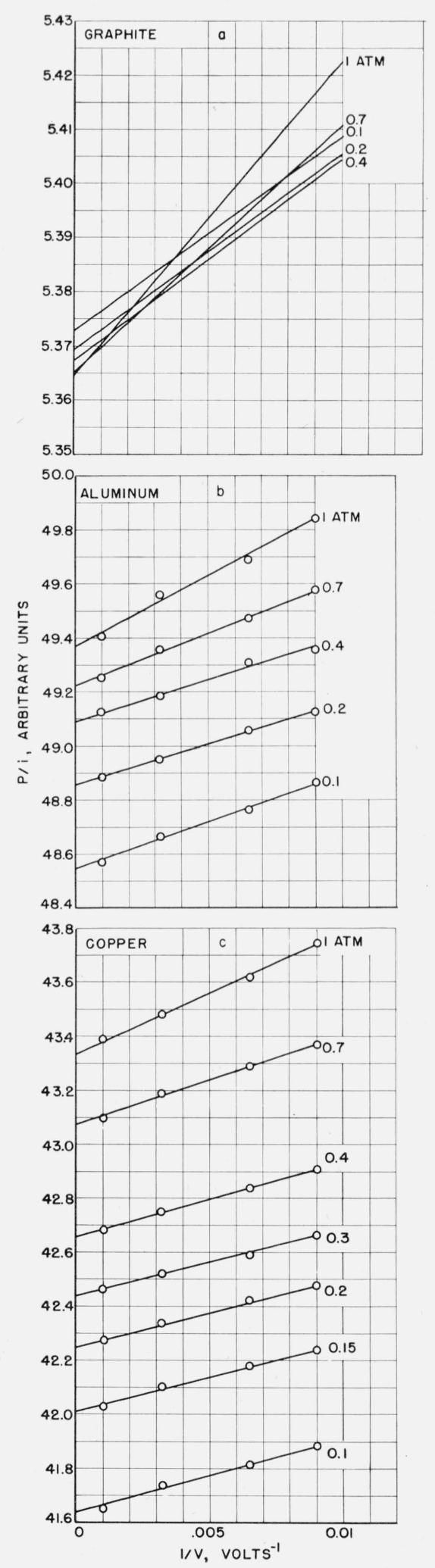

Figure $9 a, b, c$. Saturation curves at various air pressures in the graphite, aluminum, and copper chambers, respectively, for cobalt-60 $\gamma$-rays, at an exposure dose rate of about 0.05 $r / \min$. 
TABLE 2

\begin{tabular}{|c|c|c|c|c|}
\hline & $I_{\mathrm{C}}$ & $I_{\mathrm{Al}}$ & $I_{\mathrm{Cu}}$ & $I_{\text {air }}$ \\
\hline $\begin{array}{l}\text { Bakker and Segre. } \\
\text { Caldwell }\end{array}$ & $\begin{array}{l}e v \\
76.4 \\
78\end{array}$ & $\begin{array}{l}e v \\
150 \\
163.1\end{array}$ & $\begin{array}{l}e v \\
279 \\
377.5\end{array}$ & $\begin{array}{l}e v \\
80.5 \\
94.9\end{array}$ \\
\hline
\end{tabular}

those of Caldwell [46]. These are given in table 2.

For the Bakker and Segre set of $I$ values, $I_{\text {air }}$ was taken as $80.5 \mathrm{ev}$, which was found by Wilson [67] to be consistent with $I_{\mathrm{Al}}=150 \mathrm{ev} . \quad I_{\mathrm{a} \text { ir }}=94.9 \mathrm{ev}$ was obtained by multiplying the effective atomic number of $\operatorname{air}^{17}$ (7.3) by 13, which is approximately the proportionality factor found by Caldwell to relate $I$ and $Z$.

The density (or polarization) effect in the graphite, aluminum, and copper was treated according to the method of Steinheimer, using his data appropriate to the Bakker-Segre and Caldwell sets of $I$ values $[68,69]$.

The mean values of $s_{\text {air }}^{Z}$ for cobalt- $60 \gamma$-rays were calculated from the usual Bragg-Gray theory approach by integrating $s_{\text {air }}^{Z}$ over the electron energy from 0 to $T_{0}$, (the starting energy of a Compton recoil electron), and then integrating over the spectrum of starting energies [70]. Values of $\bar{s}_{\text {air }}^{Z}$ so obtained are given in table 3 for the two sets of $I$.

TABLE 3. $\bar{s}_{\text {air }}^{Z}$ for $\mathrm{Co}^{60} \gamma-$ rays $^{\mathrm{a}}$

\begin{tabular}{|c|c|c|c|}
\hline & C & $\mathrm{Al}$ & $\mathrm{Cu}$ \\
\hline $\begin{array}{l}\text { Bakker and Segre } \\
\text { Caldwell }\end{array}$ & $\begin{array}{l}1.000 \\
1.016\end{array}$ & $\begin{array}{r}0.921 \\
.928\end{array}$ & $\begin{array}{r}0.836 \\
.823\end{array}$ \\
\hline
\end{tabular}

a Bragg-Gray treatment.

These data are compared with the experimental results in figure 10 by plotting $1 / \bar{s}_{\text {air }}^{\mathrm{Cu}}, 1 / \bar{s}_{\text {air }}^{\mathrm{Al}}$, and $1 / \bar{s}_{\text {air }}^{\mathrm{C}}$ as short arrows along the vertical axis, having arbitrarily normalized to the experimental graphite curve at $0.085 \mathrm{~atm}$. These theoretical values are seen to be too low to agree with any reasonable extrapolation of the experimental curves to zero pressure, where they are meant to be applied. Furthermore, the Bragg-Gray theory has nothing to say about the variation of ionization with cavity size (or gas pressure).

The modified cavity theory of Spencer [49], on the other hand, relates $\bar{s}_{\text {air }}^{z}$ to a parameter $\Delta$, taken to be the energy needed by an electron to cross the cavity. Secondary electrons ( $\delta$-rays) produced by collisions between electrons are included in the electron flux assumed to be crossing the cavity. The flux includes only electrons with energies greater than $\Delta$, because it is assumed that all electrons with energies less than $\Delta$ lose their energy immediately, on the spot where they originate. The same general sort of calculation was carried out as was done for the Bragg-Gray theory, except that the integration over the degraded electron spectrum was taken from $\Delta$ to $T_{0}$. The resulting values of $\bar{s}_{\text {air }}^{z}$ are given in table 4 for various values of $\Delta$.

${ }_{17}$ Air was assumed to be 75.5 percent $\mathrm{N}_{2}, 23.2$ percent $\mathrm{O}_{2}$, and 1.3 percent $\mathrm{A}$, by weight.

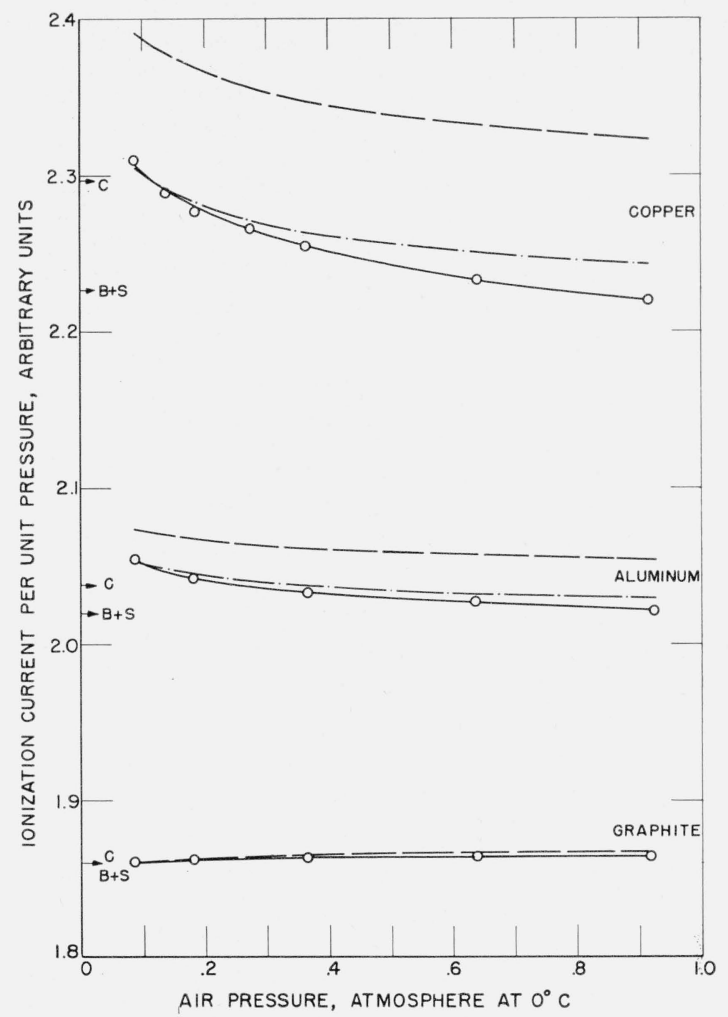

FIGURE 10. Comparison of the relative ionizations in graphite, aluminum, and copper cavity chambers with theory, for cobalt-60 $\gamma$-rays.

The solid curves represent the observed ionizations per unit pressure as a function of pressure, for $1 / v=0$ (see figs. $9 \mathrm{a}$ to $\mathrm{c}$ ). The dashed curves were obtained, theoretically, by applying Caldwell stopping-power data to the Spencer cavity theory. The "dash-dot" curves were similarly obtained by applying Bakker and Segre stopping-power data to the Spencer theory. The short arrows at the ordinate axis represent the ionizations predicted by applying Bakker and Segre (B and S) and Caldwell $(\mathrm{C})$ data to the conventional Bragg-Gray cavity theory.
The results of each theory are normalized to the graphite experimental data at The results of each theor
a pressure of 0.085 atmos.

TABLE 4. ${ }^{-Z}$ air calculated for cobalt-60 $\gamma$-rays from Spencer, cavity theory [49] a

\begin{tabular}{|c|c|c|c|c|}
\hline$\Delta(\mathrm{kev})$ & 10.2 & 20.4 & 40.9 & 81.8 \\
\hline $\begin{array}{l}\mathrm{C} \ldots \\
\mathrm{Al} \ldots \\
\mathrm{Cu}\end{array}$ & 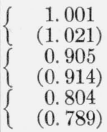 & $\begin{array}{c}1.001 \\
(1.019) \\
0.911 \\
(0.919) \\
0.817 \\
(0.803)\end{array}$ & $\begin{array}{c}1.000 \\
(1.017) \\
0.917 \\
(0.924) \\
0.828 \\
(0.815)\end{array}$ & $\begin{array}{c}1.000 \\
(1.016) \\
0.921 \\
(0.928) \\
0.837 \\
(0.825)\end{array}$ \\
\hline
\end{tabular}

a $\Delta=$ energy needed by an electron to cross the cavity. The values given in parentheses are calculated according to Caldwell's $I$ values, the others are according to Bakker and Segre.

The choice of $\Delta$ for a particular chamber shape and gas pressure is fortunately not critical, because it would be difficult to calculate with accuracy. For the present experimental chambers, the diameter of $4 \mathrm{~cm}$ was taken as the effective track length of the electrons in crossing the cavity. ${ }^{18}$ Range-energy

$183 \mathrm{~cm}$ was taken as the mean diameter of the chamber, and the electrons were assumed to have linear ranges of $\approx 0.8$ times their track lengths [71], thus giving $\approx 4 \mathrm{~cm}$ for the mean track length in the chamber. If $5 \mathrm{~cm}$ or $3 \mathrm{~cm}$ had been assumed instead of this $4 \mathrm{~cm}$ mean track length, $\bar{s}_{\text {air }}^{\mathrm{Cu}}$ would be changed by about \pm 0.4 percent, $\bar{s}_{\text {air }}^{\mathrm{Al}}$ by \pm 0.1 percent, $\bar{s}_{\text {air }}^{\mathrm{C}}$ negligibly. 
data for electrons in air were taken from Spencer [71], in relating $\Delta$ to the air pressure in the cavity.

Again normalizing the reciprocals of $\bar{s}_{\text {air }}^{\mathrm{C}}, \bar{s}_{\mathrm{air}}^{\mathrm{Al}}$, and $\bar{s}_{\text {air }}^{\text {Cu }}$ to the graphite experimental curve at $0.085 \mathrm{~atm}$, the resulting theoretical curves are shown in figure 10. The calculations based on Bakker-Segre $I$ values are clearly the closer to the experimental results. Agreement is closest at low pressures where the limitation on the theory that $\Delta \ll T_{0}$ is best satisfied, as one might expect. At higher pressures, the air in the cavity begins to modify the spectrum of electrons crossing the cavity, which is assumed to be a negligible effect in the theory. It is thus apparent that a further refinement of the theory is necessary to account more exactly for the behavior of cavities where $\Delta$ is large. The present agreement at low pressure is, however, sufficiently good to warrant the conclusion that the Bakker-Segre $I$ values, in conjunction with the modified cavity theory of Spencer, are to be preferred to the Caldwell $I$ values in predicting the relative ionization in $\mathrm{Cu}-, \mathrm{Al}-$, and $\mathrm{C}$-walled cavity chambers irradiated by cobalt- $60 \gamma$-rays.

It will be seen from the above discussion that this experiment does not directly affirm the accuracy of $I_{\mathrm{a} \text { ir }}=80.5 \mathrm{ev}$, relative to $I_{\mathrm{C}}, I_{\mathrm{Al}}$, and $I_{\mathrm{Cu}}$, because only the ratios of ionizations among the latter materials are compared. However, there are other confirmations besides Wilson's work [67] indicating that $I_{\mathrm{air}}=80.5 \mathrm{ev}$ is consistent with the BakkerSegre $I$ values.

Whyte [51] has recently suggested an empirical method for determining $\overline{\bar{s}}_{\text {air }}^{Z}$ from an interpolation between the mean slopes of the ionization/pressure versus pressure curves for different wall materials. By this method, applied to air-filled cavity chambers of copper, aluminum, graphite, and beryllium, he arrives at a value of $\bar{s}_{\text {air }}^{\mathrm{C}}=1.003 \pm 0.005$ for cobalt -60 $\gamma$-rays and $\Delta \approx 25 \mathrm{kev}$. The corresponding value from table 4, based on the Bakker-Segre $I$ data, would be $\bar{s}_{\text {air }}^{\mathrm{C}}=1.001$, in close agreement. Applying Whyte's method to our experimental curves in figure 10 , yields $\bar{s}_{\text {air }}^{\mathrm{C}}=1.007 \pm 0.005$ or 0.6 percent more than the theoretical value. This must still be considered as fair agreement, however, because this empirical method is extremely sensitive to the slope of the experimental graphite curve. For example, if the ionization per unit pressure in the graphite chamber had gradually decreased by only 0.05 percent in place of the observed 0.15 percent in going from 0.92 to $0.085 \mathrm{~atm}$, the value obtained for $\bar{s}_{\text {air }}^{\mathrm{C}}$ would have been 1.002 . This is about the range of accuracy one might expect of the graphite slope in this experiment.

Thompson [72] has recently measured the relative stopping powers of graphite, liquid nitrogen, and liquid oxygen for protons in the neighborhood of $270 \mathrm{Mev}$. His $I$ values, relative to $I_{\mathrm{Cu}}=279 \mathrm{ev}$, are $I_{\mathrm{C}}=70.2 \mathrm{ev}, I_{\mathrm{N}}=76.3 \mathrm{ev}$, and $I_{\mathrm{O}}=88.3 \mathrm{ev}$. Taking this $I_{\mathrm{N}}$ and $I_{\mathrm{O}}$ in conjunction with $I_{\mathrm{A}}=198 \mathrm{ev}$ for argon [73], one calculates $I_{\mathrm{a} 1 \mathrm{r}}=79.8 \mathrm{ev}$. The $\bar{s}_{\text {air }}^{\mathrm{C}}$ (at $\Delta=25 \mathrm{kev}$ ) resulting from these data and Spencer cavity theory becomes 1.011, including the density correction according to Sternheimer [68]. This is apparently in disagreement with $\bar{s}_{\mathrm{air}}^{\mathrm{C}}=1.001 \mathrm{ob}-$ tained from Bakker-Segre $I$ data. However, Whyte [51] has pointed out that part of the density effect, namely the "zero-energy" part, has not been taken into account here. If the Thompson measurements had compared the stopping powers of graphite with that of gaseous nitrogen and oxygen, a different value of $I_{\mathrm{a} \text { ir }}$, closer to $I_{\mathrm{C}}$, would have resulted. Sternheimer [74] has calculated the magnitude of the zero-energy density effect in solid (or liquid) air as 1.0 percent. Taking this into account corrects $\bar{s}_{\text {air }}^{\mathrm{C}}$ from 1.011 to 1.001 , in identical agreement with Bakker and Segre. Thus, there seems to be a fair amount of evidence in support of these results, and they may now be applied to the radium $\gamma$-ray measurements.

\section{Calculation of $k(\mathrm{Ra})$}

If one uses the Compton recoil-electron spectrum arising from the radium $\gamma$-ray spectrum in place of that from cobalt-60, the data for $\bar{s}_{\text {air }}^{\mathrm{C}}$ given in table 4 are increased by only about 0.06 percent at each $\Delta$, giving for the Bakker-Segre data:

$$
\begin{array}{lcccc}
\Delta(\mathrm{kev}) & 10.2 & 20.4 & 40.9 & 81.8 \\
s_{\text {air }}^{\mathrm{C}} & 1.002 & 1.001 & 1.001 & 1.000
\end{array}
$$

The dependence of the graphite-chamber ionization (per unit pressure) upon air pressure was found for radium $\gamma$-rays to be indiscernible from that $o b$ tained with cobalt-60, indicated in figure 10 . Thus, it will be seen that $k(\mathrm{Ra})$ based on the graphite chamber measurements is independent of pressure:

\begin{tabular}{|c|c|c|c|c|}
\hline Pressure & $\mathrm{esu} / \mathrm{cm}^{3} / \mathrm{mgh}$ & $\Delta$ & $\bar{s}_{\mathrm{air}}^{\mathrm{C}}$ & $k(\mathrm{Ra})$ \\
\hline $\begin{array}{c}\text { atmos } \\
1 \\
0.1\end{array}$ & $\begin{array}{l}\text { 8. } 25_{7} \\
\text { 8. } 24_{4}\end{array}$ & $\begin{array}{c}\text { kev } \\
48 \\
13\end{array}$ & $\begin{array}{l}\text { 1. } 000_{6} \\
\text { 1. } 001_{5}\end{array}$ & $\begin{array}{l}\text { 8. } 26 \\
\text { 8. } 26\end{array}$ \\
\hline
\end{tabular}

\section{Estimation of Limits of Error in $k(\mathrm{Ra})$}

(1) Effective content of radium source +0.4

(2) Chamber volume _........

(3) Compensating capacitor _... _ _ \pm 0.05

(4) Compensating potentiometer ..... \pm 0.05

(5) Interval timer $\ldots 0$

(6) Distance measurements, source-to-

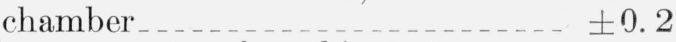

(7) Measurements of ambient temperature, pressure and humidity (combined)

(8) Measurements of scattered radiation and chamber-wall attenuation _... \pm 0.3

(9) Stopping-power correction $\left(\bar{s}_{\text {air }}^{\mathrm{C}}\right) \ldots \ldots \pm 0.3$

Combining these as random errors gives an estimated limit of error of \pm 0.6 percent for $k(\mathrm{Ra})$. Thus, we can write

$$
k(\mathrm{Ra})=8.26 \pm 0.05 \mathrm{r} / \mathrm{mgh} \text { at } 1 \mathrm{~cm} .
$$


It must be stressed that this value of $k(\mathrm{Ra})$ is based upon the validity of the conclusions reached in the discussion of the stopping-power correction $\bar{s}_{\text {air }}^{\mathrm{C}}$. Future measurements of stopping power are not expected to disagree appreciably, but that possibility cannot be ruled out, in which case the value given here for $k(\mathrm{Ra})$ can be adjusted to conform to the resulting improvements in $\bar{s}_{\text {air }}^{\mathrm{C}}$.

\section{Comparison With Results of Other Workers}

A survey of the literature on the $\gamma$-ray emission of radium reveals that this constant has been measured in no fewer than 25 separate experiments. The results of some of these measurements have been included in table 5, for comparison with the present

TABLE 5. Values of $k(\mathrm{Ra})$ obtained previously by other workers.

\begin{tabular}{|c|c|c|c|c|}
\hline \multirow{2}{*}{ Author } & \multirow[b]{2}{*}{$\begin{array}{l}\text { Type of cavity } \\
\text { chamber }\end{array}$} & \multicolumn{3}{|c|}{$\begin{array}{c}k(\mathrm{Ra}) ; \underset{\mathrm{r} / \mathrm{mgh} \text { at } 1 \mathrm{~cm}, 0.5}{\mathrm{~mm} \text { Pt filter }}\end{array}$} \\
\hline & & $\begin{array}{c}\text { Value } \\
\text { given } \\
\text { by } \\
\text { authors }\end{array}$ & $\begin{array}{c}\text { Corrected } \\
\text { for } \gamma \text {-ray } \\
\text { attenua- } \\
\text { tion in } \\
\text { cavity } \\
\text { wall }\end{array}$ & $\begin{array}{l}\text { Corrected } \\
\text { for non-air } \\
\text { equiva- } \\
\text { lence of } \\
\text { wall }\end{array}$ \\
\hline $\begin{array}{l}\text { Friedrich and } \\
\text { Schulze, } 1935 \text { [4]. }\end{array}$ & $\begin{array}{l}\text { Spherical, graphite, } 4 \\
\text { mm thick. }\end{array}$ & 7.8 & 8.0 & 8.0 \\
\hline Minder, 1937 [5] & $\begin{array}{l}\text { Spherical, graphite, } 4 \\
\text { mm thick. }\end{array}$ & 8.0 & 8.2 & 8.2 \\
\hline $\begin{array}{l}\text { Mayneord and } \\
\text { Roberts, } 1947 \text { [6]. }\end{array}$ & $\begin{array}{l}\text { Cylindrical, graphite, } \\
4 \mathrm{~mm} \text { thick. Cen- } \\
\text { tral rod of elektron } \\
\text { metal. }\end{array}$ & 8.3 & 8.3 & 8.2 \\
\hline Gray, $1937[7,8] \ldots$ & $\begin{array}{l}\text { Cylindrical, graphite, } \\
3 \mathrm{~mm} \text { thick. }\end{array}$ & 8.4 & 8.4 & 8.3 \\
\hline $\begin{array}{l}\text { Kaye and Binks, } \\
1938[9] .\end{array}$ & $\begin{array}{l}\text { Cylindrical, graphite, } \\
3 \mathrm{~mm} \text { thick. }\end{array}$ & 7. 96 & 8.1 & 8.1 \\
\hline $\begin{array}{l}\text { White, Marinelli, } \\
\text { and Failla, } 1940 \\
\text { [10]. }\end{array}$ & $\begin{array}{l}\text { Spherical Lucite shells, } \\
\text { source in center. }\end{array}$ & 8. $4_{7}$ & 8. 47 & 8.3 \\
\hline $\begin{array}{l}\text { Darden and Shep- } \\
\text { pard, } 1951 \text { [11]. }\end{array}$ & $\begin{array}{l}\text { Cylindrical, polysty- } \\
\text { rene. }\end{array}$ & 8. $3_{8}$ & 8. $3_{8}$ & 8.2 \\
\hline \multirow[t]{2}{*}{$\begin{array}{l}\text { Ghosh, Kastner, } \\
\text { and Whyte, } 1953 \\
\text { [12]. }\end{array}$} & \multirow[t]{2}{*}{$\begin{array}{l}\text { Cylindrical, polysty- } \\
\text { rene. }\end{array}$} & $8.4_{4}$ & $8.4_{4}$ & $8.2^{\mathrm{a}}$ \\
\hline & & \multicolumn{3}{|c|}{ A verage value $\ldots \ldots 8.2^{\mathrm{b}}$} \\
\hline
\end{tabular}

a This figure also includes a correction factor of 0.995 to take into account the revised value of the Canadian radium standard according to the findings of Davenport et al. [55].

b This figure is consistent with the Bakker and Segre stopping-power data. If, instead, the calculations of Laurence [34] (based upon the assumption that the mean excitation potential $1=13.5 Z$ ) are applied, the figure is changed to 8.4 , which is the currently accepted value of $k(\mathrm{Ra})$.

determination. These criteria were followed in selecting the data for this table:

(a) Free-air-chamber measurements were excluded on the grounds that, to date, none of them have been free of plate separation inadequacy, recombination losses, and/or electric field distortion.

(b) Measurements with cavity chambers having wall thicknesses inadequate for electronic equilibrium ( $\approx 3 \mathrm{~mm}$ of graphite) were omitted, as were those in which the walls were not closely air equivalent (e. g., aluminum), or were not of well-defined composition (e. g., paper). (c) Only the most recent determination by a given author was included.

The values of $k(\mathrm{Ra})$ as given by these authors vary from 7.8 to $8.4_{7}$, a spread of nearly 9 percent. However, if one applies corrections for attenuation of $\gamma$-rays in the cavity wall in cases where this was not included, and for the non-air-equivalence of the wall material (in accordance with the Bakker and Segre stopping-power results), the spread of results is reduced to 4 percent, and the average value is 8.2 $\mathrm{r} / \mathrm{mgh}$ at $1 \mathrm{~cm}$.

Another correction which has apparently been omitted from all these measurements (except that of Gray [7]), judging from the fact that it was not mentioned, is the correction for the decrease in electron density of the air, owing to humidity. This will be an upward correction to $k(\mathrm{Ra})$, usually in the neighborhood of 0.3 percent. Thus, the 8.2 figure should be increased by roughly this amount. The resulting number for $k(\mathrm{Ra})$ lies within the experimental error of the present result of 8.26 $\pm 0.05 \mathrm{r} / \mathrm{mgh}$ at $1 \mathrm{~cm}$. Considering the many factors entering into such measurements, such close agreement may be to some extent fortuitous. However, it does indicate that $k(\mathrm{Ra})$ is probably known with better accuracy than has been heretofore supposed.

Another interesting experiment was carried out by Gray [7], who applied cavity-ionization methods to determine the total energy absorbed in a large aluminum block enclosing a radon capsule. Gray averaged his result with a value obtained calorimetrically by Zlotowski [75] and arrived at $8.7_{5}$ $\mathrm{cal} / \mathrm{hr}$ per gram of radium (in equilibrium with its daughter products) as the best figure for the total $\gamma$-ray energy output. This can be reduced to a value for $k(\mathrm{Ra})$ by application of eq 4 in Gray's paper, using $\left(\sigma_{\mathrm{a}}\right)_{\mathrm{air}}=0.0892 \times 10^{-24} \mathrm{~cm}^{2} /$ electron and $\mathrm{W}_{\mathrm{a} \text { ir }}=33.7 \mathrm{ev}$ per ion pair as given by Bay et al. [76]. The resulting value for $k(\mathrm{Ra})$ is $9.0_{0} \mathrm{r} / \mathrm{mgh}$ at $1 \mathrm{~cm}$ (for zero filtration of the radium source). The data of Whyte [58] indicate a transmission of $0.90_{8}$ through $0.5 \mathrm{~mm}$ of platinum; thus, $k(\mathrm{Ra})$ is given as $8.1_{7} \mathrm{r} / \mathrm{mgh}$ at $1 \mathrm{~cm}$; in reasonably good agreement with the results obtained by conventional cavity-chamber methods. Conversely, if one assumes $8.26 \mathrm{r} / \mathrm{mgh}$ at $1 \mathrm{~cm}$ for the value of $k(\mathrm{Ra})$, the total $\gamma$-ray energy output becomes $8.84 \mathrm{cal} / \mathrm{hr} / \mathrm{g}$ Ra. This is in good agreement with Zlotowski's result of $9.1 \pm 0.15 \mathrm{cal} / \mathrm{hr} / \mathrm{g} \mathrm{Ra}$, if one applies to it a correction factor of 0.98 for geometrical error and multiple scattering of $\gamma$-rays, as suggested by Gray, yielding a value of $8.9 \pm 0.15 \mathrm{cal} / \mathrm{hr} / \mathrm{g} \mathrm{Ra}$.

The authors thank H. O. Wyckoff for frequent discussions on the various phases of the work; L. V. Spencer for his contributions in the interpretation of the cavity-chamber measurements; and W. B. Mann for his calibration of the radium source by the calorimetric method. 


\section{References}

[1] 1956 Report of the International Commission on Radiological Units and Measurements.

[2] L. H. Gray, Proc. Roy. Soc. (London) [A] 156, 578 (1936).

[3] W. H. Bragg, Studies in radioactivity, p. 94 (MacMillan and Co., New York, N. Y., 1912).

[4] W. Friedrich and R. Schulze, Strahlentherapie, 54, 553 (1935)

[5] W. Minder, Acta Radiol. 17, 761 (1937).

[6] W. V. Mayneord and J. E. Roberts, Brit. J. Radiol. 10, 365 (1937).

[7] L. H. Gray, Proc. Roy. Soc. (London) [A] 159, 263 (1937).

[8] L. H. Gray, Brit. J. Radiol. 10, 721 (1937).

[9] G. W. Kaye and W. Binks, Am. J. Roentgenol. and Radium Therapy 40, 80 (1938).

[10] T. N. White, L. D. Marinelli, and G. Failla, Am. J. Roentgenol. and Radium Therapy 44, 889 (1940).

[11] E. B. Darden and C. W. Sheppard, Oak Ridge National Laboratory Report No. 1002 (Instrumentation, July 9, 1951).

[12] A. Ghosh, J. Kastner, and G. N. Whyte, Nucleonics 11, No. 6, $70(1953)$

[13] A. S. Eve, Phil. Mag. 22, 551 (1911).

[14] A. S. Eve, Phil. Mag. 2\%, 394 (1914).

[15] H. Behnken and R. Jaeger, Strahlentherapie 29, 483 (1928).

[16] M. Jona, Strahlentherapie 32, 775 (1929).

[17] M. Bruzau, Ann. phys. 11, 1 (1929).

[18] O. Glasser and F. R. Mautz, Radiology 15, 93 (1930)

[19] G. Failla and P. S. Henshaw, Radiology 1\%, 1 (1931).

[20] W. V. Mayneord, Brit. J. Radiol. 4, 693 (1931).

[21] A. W. Reitz, Z. Physik 69, 259 (1931).

[22] W. V. Mayneord, Brit. J. Radiol. 6, 598 (1933).

[23] R. Paterson and H. M. Parker, Brit. J. Radiol. 7, 592 (1934)

[24] R. M. Sievert, Acta Radiol. 15, 193 (1934).

[25] W. Friedrich, K. G. Zimmer, and R. Schulze, Strahlentherapie 51, 7 (1934).

[26] W. V. Mayneord and J. E. Roberts, Brit. J. Radiol. y, $158(1934)$

[27] L. G. Grimmett and J. Read, Brit. J. Radiol. 8, 702 (1935)

[28] W. Friedrich, Strahlentherapie 54, 397 (1935).

[29] J. Murdoch and E. Stahel, Strahlentherapie 53, 102 (1935)

[30] G. W. C. Kaye and W. Binks, Strahlentherapie 56, 608 (1936).

[31] J. Murdoch, E. Stahel, and S. Simons, Strahlentherapie $\mathbf{5 \%}, 87(1936)$

[32] O. Glasser and L. Rovner, Am. J. Roentgenol. and Radium Therapy 36, 94 (1936).

[33] K. G. Zimmer, Radiumdosimetrie, Georg Thieme, Leipzig (1936).

[34] G. C. Laurence, Can. J. Research 15, 67 (1937).

[35] G. Failla and L. D. Marinelli, Am. J. Roentgenol. and Radium Therapy 38,312 (1937)

[36] H. Smereker, Strahlentherapie 58, 267 (1937).

[37] R. Schulze, Ann. Physik 31, 633 (1938).

[38] W. Friedrich, Am. J. Roentgenol. and Radium Therapy 40, 69 (1938).

[39] G. C. Laurence, Am. J. Roentgenol. and Radium Therapy 40, 92 (1938).

[40] L. Rovner, Am. J. Roentgenol. and Radium Therapy 40, 104 (1938).
[41] W. Minder, Radiumdosimetrie (Julius Springer, Vienna, 1941).

[42] L. S. Taylor and G. Singer, J. Research NBS 24, 247 (1940) RP1283.

[43] H. A. Bethe and J. Ashkin, Experimental nuclear physics, E. Segre, Ed., Vol. I, p. 254 (eq 52) (John Wiley \& Sons, Inc., New York, N. Y., 1953).

[44] C. J. Bakker and E.'Segre, Phys. Rev. 81, 489 (1951).

[45] R. L. Mather and E. Segre, Phys. Rev. 84, 191 (1951).

[46] D. O. Caldwell, Phys. Rev. 100, 291 (1955)

[47] H. Bichsel and R. F. Mozley, Phys. Rev. 94, 764 (1954).

[48] W. Brandt, Phys. Rev. 104, 691 (1956).

[49] L. V. Spencer and F. H. Attix, Rad. Research 3, 239 (1955).

[50] R. K. Clark and S. S. Brar, Nucleonics 12, No. 8, 28 (1954).

[51] G. N. Whyte, Rad. Research 6, 371 (1957)

[52] J. R. Greening, Brit. J. Radiol. 30, 254 (1957).

[53] J. W. Boag, Radiation dosimetry, ed. Hine and Brownell, p. 194 (Academic Press Inc., New York, N. Y., 1956).

[54] L. Costrell and F. H. Attix, Nucleonics 15, No. 2, 203 (1957).

[55] T. I. Davenport, W. B. Mann, C. C. MeCraven, and C. C. Smith, J. Research NBS, 53, 267 (1954) RP2544.

[56] W. E. Perry, Proc. Phys. Soc. London [A], 68, 942 (1955)

[57] E. A. Owen and B. Naylor, Proc. Phys. Soc. London 34, 92 (1922)

[58] G. N. Whyte, Brit. J. Radiol. 28, 635 (1955).

[59] C. C. Paterson, J. W. T. Walsh, and W. F. Higgins, Proc. Phys. Soc. London 29, 215 (1917).

[60] W. B. Mann, J. Research NBS 53, 277 (1954) RP2545.

[61] C. W. Wilson, Radium therapy, its physical aspects, p. 72 (Chapman Hall, London, 1948)

[62] W. V. Mayneord, Brit. J. Radiol., Suppl. No. 2, 226 (1950).

[63] Gladys White Grodstein, X-ray attenuation coefficients, NBS Circ. 583 (1957)

[64] C. M. Davisson and R. D. Evans, Phys. Rev. 81, 404 (1951).

[65] E. Kara-Michailova and D. E. Lea, Proc. Cambridge Phil. Soc. 36, 101 (1940).

[66] L. B. Loeb, Fundamental processes of electrical discharge in gases, p. 338 (John Wiley \& Sons, Inc., New York, N. Y., 1939)

[67] R. R. Wilson, Phys, Rev, 60, 749 (1941).

[68] R. M. Sternheimer, Phys. Rev. 88, 851 (1952).

[69] R. M. Sternheimer, Phys. Rev. 103, 511 (1956).

[70] A. T. Nelms, Graphs of the Compton energy-angle relationship and the Klein-Nishina formula from 10 kev to 500 mev, NBS Circ. 542 (1953)

[71] L. V. Spencer, Phys. Rev. 98, 1, 597 (1955).

[72] T. J. Thompson, Effect of chemical structure on stopping powers for high-energy protons, UCRL-1910, University of California Thesis (August 11, 1952).

[73] W. A. Aron, The passage of charged particles through matter, UCRL-1325, University of California Thesis (Mav 1951).

[74] R. M. Sternheimer, Phys. Rev. 93, 351 (1953).

[75] I. Zlotowski, J. phys. radium 6, 241 (1935).

[76] Z. Bay, W. B. Mann, H. H. Seliger, and H. O. Wyckoff, $\mathrm{W}_{\text {air }}$ for sulphur-35 beta rays, Rad. Research (to be published).

Washington, March 15, 1957. 